\title{
A study of Aggregate Costs of Quarantine for COVID-19 in Wuhan
}

\author{
Zihan Zheng \\ SILC Business School, Shanghai University No.20 Cheng Zhong Road, 201899 Shanghai, P.R.China.
}

Keywords: COVID-19, Wuhan, Quarantine costs, Tertiary industry, Economic impact.

\begin{abstract}
Coronavirus Disease 2019 (COVID-19) in Wuhan has spread rapidly across the country, and many oversea countries have also identified some confirmed cases. To prevent further spread of the epidemic, Wuhan has sealed off the city from all outside contact. The purpose of this study is to estimate the total costs of quarantine in Wuhan. Because the outbreak has not over yet, this article made educated estimations based on past data and referred to a model to calculate the number of contacts and infected cases. By summing the administrative costs, losses in tourism \& hotel and catering \& export \& public transportation \& entertainment industries and lost productivity, the aggregate costs of quarantine in Wuhan is around 70 billion yuan. This result provides a general idea of how the tertiary industry will be impacted and is useful for government and companies to adjust financial deficit and future budget so as to alleviate the influence of COVID-19.
\end{abstract}

\section{Introduction}

In December 2019, some medical institutions in Wuhan began to receive pneumonia patients with unknown causes. After investigation, it is caused by the virus originated in Huanan Seafood Market in Wuhan and the World Health Organization (WHO) named it 2019-nCoV. This type of pneumonia is named as Corona Virus Disease 2109 (COVID-19). Although its death rate is lower than that of SARS, the transmission rate is much higher, especially during the Spring Festival when there were a large stream of people travelling around. By 1 March 2020, 80302 cases were identified with 49315 cases occurring in Wuhan and among these cases, 2227 leaded to death [1].

To prevent the spread of the epidemic to other regions and control the source of infection, Wuhan has been sealed off since January 23, 2020. Quarantine is a common method to prevent the spread of infection and generally considered to be effective. However, the staggering cost that quarantine might bring can not be neglected. Besides, the economic impact of this outbreak will be even more severe than SARS. SARS had a small impact on the economy of the whole country and Guangdong province because economic development in China was in a strong upward trend during that time. While at present, macro environment is more complex and severe. Thus, it is necessary to estimate the loss that COVID-19 may incur, which has important implications for government and some institutions to adjust fiscal deficits, future investments in public health, and budget projections for the next time facing a similar potential disaster. Although many recent researches have predicted that COVID-19 could knock 1.2 percentage points off China's GDP [2], few are able to give a concrete number of loss, especially in Wuhan. This paper attempts to answer what is the total quarantine costs in Wuhan so that relevant supporting policies can be formulated as soon as possible.

The overall structure of the study takes the form of five sections, including research background, goal and question in the introduction, literature review of presented studies, research results and analysis in the third part, discussion and finally conclusion.

\section{Literature Review}

Quarantine is to place infectious source (infectious patients and carriers) and highly susceptible people or close contacts in specific places and special environment to temporarily avoid contacting with the surrounding people. For the former, isolation of infectious source is adopted to prevent infectious disease pathogens from spreading outward, while for the latter, protective isolation is 
adopted to protect highly susceptible people from infection. When the source of infection is unknown and there are also no effective drugs, quarantine is a classic and common public health intervention.

The economic impact would be predicted, estimated and discussed for each pandemic because of the huge losses but also potential new opportunities. Richard and David point out that the actual losses were smaller than predicted during the SARS outbreak by using the actual data [3]. Li concludes that the tertiary industry like consumption and service industries will be most affected and delayed resumption of work also has an impact on industrial production and exports [4]. Wang states that flight cancellations because of COVID-19 may outstrip the worst period of SARS [5]. Xiao predicts that the influence of import and export trade in Guangzhou is far greater than SARS by listing five reasons [6]. On the positive side, Feng and Zhang propose that the overall impact on large logistics companies is positive due to the increase of people's demand for online shopping under the emergency period [7]. Liu also indicates that COVID-19 may promote the development of online mental health services and explore new markets [8].

Much of the current literature pays particular attention to the country as a whole and uses GDP as an indicator to measure the loss. However, the concrete value of the loss remains unknown. Although, Anu G. et al. have derived the model to calculate the costs of SARS quarantine in Toronto, the author only took into account the lost productivity and administrative cost and have not treated the lost revenue of tertiary industry in much details [9]. Additionally, it is the first time for China to quarantine the entire city. Few studies have investigated how much will it cost. This research attempts to measure the quarantine costs in Wuhan from a more comprehensive perspective and assess a specific aggregate value. It is expected to provide valuable information and implications for government and companies to timely adjust the budget and output. Because epidemic situation is not over yet, accurate case information cannot be acquired. Relevant information is calculated (illustrated in 3.1) based on the model Anu G. et al. have derived [9]. And the impact of the outbreak is expected to focus on the first quarter [10].

\section{Research Result and Analysis}

\subsection{Number of contacts and infected people}

Several variables that influence the transmission rate of SARS defined by Anu G. et al. are as follows [9]. $\boldsymbol{k}$ represents the number of contacts, which is the function of $\boldsymbol{\rho}$, population density, and $\boldsymbol{\delta}$, the incubation period of SARS. $\boldsymbol{k}$ can be regard as a constant number.

$$
k=f(\rho, \delta)
$$

For different scenarios and diverse types of individuals, the transmission rate of SARS is also heterogeneous. People who work in public places, such as hospitals and stations, are more susceptible. The infection rate in families with infected member is normally higher than average. Thus, the author established a model based on the index case: ( $\boldsymbol{\alpha}$, efficiency of transmission; $\boldsymbol{x}_{\boldsymbol{i}}$, the number of infected people at $\boldsymbol{i}$ stage)

$$
\begin{gathered}
\text { Primary infectious }\left(x_{1}\right)=k \alpha(2) \\
\text { Secondary infectious }\left(x_{2}\right)=x_{1} k \alpha \\
\text { Tertiary infectious }\left(x_{3}\right)=x_{2} k \alpha \\
\text { Total number of infectious }=1+\sum\left(x_{i}\right)(3) \\
\text { Total number of exposures }=k \sum\left(x_{i}\right)(4)
\end{gathered}
$$

Because SARS in 2003 and COVID-2019 are both corona virus infections with the same infection site, lung, and the same route of transmission, which is through respiratory tract. As a consequence, this article will use the same model to estimate the situation of COVID-19 and the result is shown in Table 1. The population density of Wuhan in 2020 was reported as 1655 people per square kilometer, which is almost twice bigger than that in Toronto. Based on the inference Anu 
G. et al. made, this article assumes that a person contacts an average of 20 different people a day. The incubation period is normally from 3 to 14 days, although a case with the longest incubation period of 24 days were found, 14 days would be used in calculation. Therefore, the index case could put 280 people at risk from the virus. The transmission rate, $\boldsymbol{\alpha}$, is greatly varied across different circumstances and this essay refers to the same data used in the original article.

Table 1 Transmission results from index case.

\begin{tabular}{|c|c|c|c|c|c|c|}
\hline & \multicolumn{2}{|c|}{$\alpha=0.08$} & \multicolumn{2}{c|}{$\alpha=0.15$} & \multicolumn{2}{c|}{$\alpha=0.25$} \\
\hline $\begin{array}{c}\text { Stage of } \\
\text { infection }\end{array}$ & $\begin{array}{c}\text { Number of } \\
\text { contacts }(k)\end{array}$ & $\begin{array}{c}\text { Number of } \\
\text { infected }\left(x_{i}\right)\end{array}$ & $\begin{array}{c}\text { Number of } \\
\text { contacts }(k)\end{array}$ & $\begin{array}{c}\text { Number of } \\
\text { infected }\left(x_{i}\right)\end{array}$ & $\begin{array}{c}\text { Number of } \\
\text { contacts }(k)\end{array}$ & $\begin{array}{c}\text { Number of } \\
\text { infected }\left(x_{i}\right)\end{array}$ \\
\hline $\begin{array}{c}\text { Primary } \\
\text { infectious }\end{array}$ & 280 & 22 & 280 & 42 & 1,764 & 70 \\
\hline $\begin{array}{c}\text { Secondary } \\
\text { infectious }\end{array}$ & 6,160 & 492 & 11,760 & 74,600 & 3400 \\
\hline $\begin{array}{c}\text { Tertiary } \\
\text { infectious }\end{array}$ & 137,760 & 11,020 & 493,920 & $7,372,000$ & 343,000 \\
\hline $\begin{array}{c}\text { Aggregate } \\
\text { infectious }\end{array}$ & 144,200 & 11,534 & 505,960 & 75,894 & $1,391,880$ & 347,970 \\
\hline
\end{tabular}

\subsection{Administrative costs}

The first cost is associated with administrative cost. Wuhan has already set up administrative infrastructures like Huo Shenshan hospital and several new container hospitals to provide more medical support and carry out quarantine. So far, the Ministry of Finance has urgently allocated a total of 1.5 billion yuan in subsidies to Hubei Province and has also issued an additional investment of 300 million yuan to support the hospital construction in Wuhan with emphasis on the purchase of necessary medical equipment. Due to the lack of concrete information and unreality to separate the cost of quarantine from total expenditure, this essay will make educated estimates based on the number of confirmed cases (showed in Table 2). Thus, the total estimated administrative cost in Wuhan is 1.35 billion yuan.

Table 2 Expenditure allocation to Wuhan based on confirmed cases.

\begin{tabular}{|c|c|c|}
\hline & Hubei Province & Wuhan \\
\hline $\begin{array}{c}\text { Confirmed cases } \\
\text { (by 21st February) }\end{array}$ & 63,454 & 45,660 \\
\hline The proportion & 100 & 70 \\
\hline Expenditure allocation (billion) & 1.5 & 1.05 \\
\hline
\end{tabular}

\subsection{Loss in Tourism Industry}

The second part is related to the huge loss in tourism industry. Almost the entire industry is at a standstill. Table 3 illustrates tourism revenue of Spring Festival Holiday from 2014 to 2019 using the data from the official website of Wuhan Culture and Tourism Administration [11]. The relevant data in 2020, 7.753 billion yuan, can be estimated by averaging the increases from 2014 to 2019 and adding it to the 2019 value [12]. Here only takes the loss during the Spring Festival into consideration because the revenue of tourism industry in the first quarter mainly comes from the Spring Festival Golden Holiday.

Table 3 Tourism revenue of Spring Festival Holiday in Wuhan.

\begin{tabular}{|c|c|c|}
\hline Year & Total Revenue (a billion yuan) & Increase by (a billion yuan) \\
\hline 2014 & 2.425 & --- \\
\hline 2015 & 2.839 & 0.414 \\
\hline 2016 & 4.283 & 1.444 \\
\hline 2017 & 5.519 & 1.236 \\
\hline 2018 & 6.226 & 0.707 \\
\hline 2019 & 6.865 & 0.639 \\
\hline 2020 & 7.753 & $0.888^{*}$ \\
\hline
\end{tabular}

(*: the average value) 


\subsection{Hotel and Catering Industry}

Along with the heavy hit in the tourism industry, the situation in hotel and catering industries is also not optimistic. Normally, demand for hotels in the Spring Festival is 16 percent higher than usual [2]. However, according to the incomplete statistics, since the Spring Festival, the occupancy rate of major hotels has declined by more than 80 percent and many of their occupancy rates were less than 4 percent, far lower than 30 to 40 percent in SARS [13]. Also in order to avoid crowd gathering, almost all kinds of dinners and wedding banquets were canceled, and a large number of restaurants were closed. Table 4 shows total retail sales of accommodation and catering industry (from January to April) using the data from Wuhan Statistics Department and the same method in 3.3 was used to estimate the data in 2020. 80 percent of this data is considered to be the loss of quarantine, which is around 19 billion yuan.

Table 4 Total retail sales of accommodation and catering industry in Wuhan (January to April).

\begin{tabular}{|c|c|c|}
\hline Year & $\begin{array}{c}\text { Retail sales } \\
\text { (a billion yuan) }\end{array}$ & $\begin{array}{c}\text { Increase by } \\
\text { (a billion yuan) }\end{array}$ \\
\hline 2016 & 16.93 & 1.7 \\
\hline 2017 & 18.63 & 1.82 \\
\hline 2018 & 20.45 & 1.85 \\
\hline 2019 & 22.30 & \\
\hline 2020 & 24.09 & \\
\hline
\end{tabular}

\subsection{Export}

Workers cannot go out for work and when will they return to work is still a question. Long term stoppage results in the failure of the enterprises to start on time, which will seriously affect the production and delivery of export products. The existing orders can not be produced and orders that already produced can not be delivered abroad as promised. Additionally, even they can produce, WHO has identified COVID-19 as Public Health Emergency of International Concern (PHEIC). Although travel and trade restrictions are not recommended, exports will still be greatly affected [14]. As the epidemic situation escalates into an international event, foreign countries will raise the entry threshold or may directly prohibit the entry of commodities from the pandemic area. In recent years, influenced by Sino US trade war and downward pressure on the economy, the growth rate of export volume in Wuhan was low. Thus, conservative estimation of export loss incurred by quarantine was derived by averaging the export volume in 2018 and 2019 (January to April), which is 35.3 billion yuan (shown in Table 5).

Table 5 Export volume in Wuhan (January to April).

\begin{tabular}{|c|c|}
\hline Year & Export volume(billion yuan) \\
\hline 2018 & 33.79 \\
\hline 2019 & 36.81 \\
\hline 2020 & 35.3 \\
\hline
\end{tabular}

(Data-source: Wuhan Statistics Department [15])

\subsection{Public transportation}

Wuhan Spring Transportation Office has previously forecast that during the Spring Festival of 2020, railways (10.74 million), highways (2.5 million) and airlines (1.76 million) were expected to send 15 million passengers in total, which is 0.5 percent higher than last year. However, the mayor of Wuhan announced at a press conference that around five million people left Wuhan before the city was closed. In other words, there are 10 million people who cannot leave the city as expected. According to the forecasting of Wuhan Spring Transportation Office, the destinations of railway passengers are concentrated in Beijing, Guangzhou, Shenzhen, Chongqing, Sichuan and Pearl River Delta area. The average railway price to these places was calculated using the data from 12306 
CHINA RAILWAY website, which is about 450 yuan per person, and then multiplied 10 million people to roughly estimate the loss from public transportation which is 4.5 billion yuan [16].

\subsection{Entertainment}

In addition to tourism and catering, another popular consumption during Spring Festival is the movies. The box office of Spring Festival has shown a high growth trend since 2014 and there are also many films that choose to be shown at this golden period [17]. This year was no exception and according to China Securities Journal, the box office was expected to hit 7 billion yuan during Spring Festival holiday [18]. Nevertheless, as densely-populated places, all cinemas in Wuhan have been asked to suspend their business. To estimate the loss in the film industry caused by quarantine, this article refers to the data in 2019. The percentage of box office in Wuhan as the national box office was calculated in Table 6 and multiplied the expected value in 2020 to get final lost in film industry.

Table 6 Lost box office in Wuhan during Spring Festival.

\begin{tabular}{|c|c|}
\hline Total national box office in 2019 & 64.266 billion yuan \\
\hline 2019 box office in Wuhan & 1.54 billion yuan (2.4\%) \\
\hline $\begin{array}{c}\text { National box office of Spring Festival in } \\
2020 \text { (Expected) }\end{array}$ & 7 billion yuan \\
\hline Lost box office in Wuhan & 0.168 billion yuan \\
\hline
\end{tabular}

(Data-source: China Securities Journal, Hubei Daily)

\subsection{Lost productivity}

It is obvious that quarantined workers are unable to work and thus, many companies would suffer from reduced productivity. Lost productivity can be regarded as indirect cost of quarantine because productivity cannot be measured directly. Anu G. et al. points out that foregone income can be used to represent lost productivity [9]. The daily wage of workers in Wuhan, $\boldsymbol{\omega}$, equals to 295 yuan [19]. And the total days that most people quarantine for are the incubation period of COVID$2019, \delta$, which is normally 14 days. Consequently, total indirect costs linked to quarantine are showed in Table 7.

Total indirect costs of quarantine $=k \delta \omega$

Table 7 Lost productivity in Wuhan.

\begin{tabular}{|c|c|c|c|}
\hline \multirow{3}{*}{$\boldsymbol{\alpha}=0.08$} & Spread of infection & Number of contacts quarantine & $\begin{array}{c}\text { Lost productivity (billion } \\
\text { yuan) }\end{array}$ \\
\cline { 2 - 4 } & Primary wave & 280 & 0.001 \\
\cline { 2 - 4 } & Secondary wave & 6440 & 0.026 \\
\hline \multirow{3}{*}{$\boldsymbol{\alpha}=0.15$} & Tertiary wave & 144,480 & 0.6 \\
\cline { 2 - 4 } & Primary wave & 280 & 0.001 \\
\cline { 2 - 4 } & Secondary wave & 12,040 & 0.05 \\
\hline \multirow{3}{*}{$\boldsymbol{\alpha}=0.15$} & Tertiary wave & 506,240 & 2.09 \\
\cline { 2 - 4 } & Primary wave & 280 & 0.001 \\
\cline { 2 - 4 } & Secondary wave & 19,880 & 0.082 \\
\hline
\end{tabular}

\subsection{Total cost of quarantine}

Till 1 March 2020, the cumulative confirmed cases in Wuhan are 49315 in total, which is the closest to the infected cases assessed by $\boldsymbol{\alpha}=0.15$ in our model (75,894 cases). Although Yan et al. have established a new delay dynamic model and inferred that the transmission rate of COVID-19 
in Wuhan was 0.1957, this value was based on the number of confirmed cases and cured cases from January 23 to February 1 [20]. Considering that the outbreak is not over yet and the number of confirmed cases is still increasing, this article will still use the data with a transmission rate of 0.15 in tertiary wave in the following calculation.

Based on all information above, aggregate costs can be estimated now (summarized in Table 8).

Table 8 Total costs of quarantine.

\begin{tabular}{|c|c|}
\hline Costs/Loss in... & Numerical value (billion yuan) \\
\hline Administrative cost & 1.35 \\
\hline Tourism industry & 7.753 \\
\hline Hotel and catering industry & 19 \\
\hline Export & 35.3 \\
\hline Public transportation & 4.5 \\
\hline Entertainment & 0.168 \\
\hline Lost productivity & 2.09 \\
\hline Aggregate amount & 70.161 \\
\hline
\end{tabular}

The result shows that the aggregate costs of quarantine in Wuhan is about 70 billion yuan and the top two are export, hotel and catering industries. However, it should be acknowledged that the result may be bias. Firstly, due to the availability of data, this paper did not unify the data time. The losses from tourism, public transportation and entertainment were measured by data during the Spring Festival and may be underestimated. While data from January to April was used to measure losses of export, hotel and catering industries. Thus, the result may be higher than reality. This can be explained by the fact that the service industry like tourism and entertainment was severely hit because the epidemic happened during the Spring Festival and the revenue from Spring Festival often accounts for a large part of the industry's revenue in the first quarter. However, the influence on export as well as hotel and catering industries may be long-term because the fear of epidemic may persist even if the crisis has been removed. Secondly, not all contacts can be effectively and timely isolated due to the lack of medical resources. One effective way is self isolation and staying at home, which incurs a little or almost no costs. On the other hand, here is only a simple and rough estimation of the overall costs and limits to the costs directly related to outbreak and quarantine. Other costs like emotional and psychological costs for health care workers, economic effects of hospitals especially used for epidemic prevention should also be taken into consideration.

\section{Discussion}

The analysis presented in this paper shows that the COVID-19 will negatively and heavily affect industries that depend on population movements and interactions among people. The losses in tourism, hotel and catering, export, public transportation, entertainment were calculated using different estimation methods and the aggregate amount of costs is around 70 billion yuan. This leads to one important indication from this work when considering the role of media in spreading information about epidemic. The economic impact largely depends on the extent to which people reduce public interaction, which could be greatly influenced by how media reports the news and what kind of attitude they hold. Negative information may increase the fear of public and decrease the demand.

This indication is particularly important and useful for international trade. The government should make a good disclosure of information to foreign countries, strengthen the communication with foreign trade organizations and institutions, eliminate the information asymmetry, and reduce the distrust from foreign investors caused by the lack of information on China's situation, so as to reduce the impact of the epidemic on foreign trade.

More attention on media also suggests that more and more people believe that network information is reliable and use the internet not only for fun but also for acquiring valuable messages. 
Plus the occurrence of this pandemic, it is a good opportunity to develop the internet health-care industry so that people can seek medical advice at home. The outbreak of COVID-19 also exposed a problem, that is, in most cities in the central region, including Wuhan, per capita medical facilities is low and cannot meet all medical needs. The government may take this opportunity to vigorously promote reform, support and develop new business models in health-care sector, internet medical industry. The combination of the internet, IT and hospitals can greatly deal with the shortage and uneven distribution of medical resources and also provide new investment opportunities.

\section{Conclusion}

The outbreak of the COVID-19 has a great impact on the social production, life order and the macroeconomic situation in a short period of time. Compared with the previous SARS, COVID-19 is relatively mild but more transmissible. Thus, the earlier quarantine measures are taken, the more effective they can be [21]. The purpose of this paper was to assess the total costs associated with quarantine of COVID-19 in Wuhan, which is about 70 billion yuan. The research also identified concrete lost value in different aspects and tried to analyze in a more comprehensive way. The finding suggests that, in general, pandemic like COVID-19 hits tertiary industry most because the performance of service sectors is largely determined by people's willingness to consume and degree of demand. And media plays an important role in disseminating information and influencing people's intentions. Although the aggregate amount of costs is enormous, quarantine can save numerous lives and thus, save the money. With the support from the government and a better public health system, we will certainly be able to overcome this disaster in the near future. However, after this painful lesson, we human should seriously consider the importance of harmonious development between economy and society and coexistence between man and nature. The government should also figure out effective ways to deal with the shortage of medical resources, such as to support the development of internet healthcare.

\section{References}

[1] Real time epidemic tracking analysis 2020, viewed 3 March 2020, <https://www.360kuai.com/mob/subject/400?sign=360_6aa05217>.

[2] Huang, Y. (2020), COVID-19: economic impact and policy responses, SPOTLIGHT, (C)19942020, pp. 76-77.

[3] SINA FINANCE (2020), It is expected that the withdrawal of 7 billion box office tickets during the Spring Festival will have an immeasurable impact on the whole year, China Securities Journal, $<$ https://baijiahao.baidu.com/s?id=1656515760052690552>.

[4] Li, W. \& Zhang, G. (2020), Comparison between COVID-19 and SARS and impact on Chinese economy, China Business News, vol. AII, pp. 1-4.

[5] Wang, Z. \& Lu, F. (2020), Impact of COVID-19 on aviation industry and preliminary strategy, China Aviation News, 008, pp. 1-3.

[6] Xiao, K., Wan, S., Xu, S. (2020), Impact of COVID-19 on Guangdong's Foreign Trade and Countermeasures, Economy of Guangdong, pp.9-14.

[7] Feng, D. \& Zhang, C. (2020), Discussion on the influence of COVID-19 on logistics industry in China, Modern logistics newspaper (CN13-0031), vol. A02.

[8] Liu, S. (2020), Online mental health services in China during the COVID-19 outbreak, Lancet Psychiatry 2020, <https://doi.org/10.1016/S2215-0366(20)30077-8>.

[9] Anu, G., Cheryl, A. \& David, T. (2004), The economic impact of quarantine: SARS in Toronto as a case study, Journal of Infection (2005), vol. 50, pp. 386-393.

[10] Guo, X. (2020), The impact of the COVID-19 on the economy and the Countermeasures', 
China financial and economic news, 007.

[11] Wuhan Culture and Tourism Administration 2019, Statistical List and Histogram of Main Data on Spring Festival Holiday Tourism from 2014 to 2018, viewed 22 February 2020, <http://wlj.wuhan.gov.cn/html/zwgktjsj/20190220/11989.html>.

[12] Richard, K. \& David, S. (2008), The economic impact of SARS: How does the reality match the predictions?, Health Policy (2008), vol. 88, pp. 110-120.

[13] CBN (2020), The sluggish consumer industry in the Spring Festival: an average loss of 17.8 billion yuan in a day of stagnation in the tourism industry, viewed 1 March 2020, <http://www.360doc.com/content/20/0203/14/77611_889435860.shtml>.

[14] Sohrabi, C., Alsafi, Z., O’Neill, N., Khan, M., Kerwan, A., Aljabir, A., Iosifidis, C., Agha, R. (2020), World Health Organization declares Global Emergency: A review of the 2019 Novel Coronavirus (COVID-19), International Journal of Surgery, IJSU 5293.

[15] Wuhan Statistics Department, From January to April, the city's economic operation is stable and rising, 2016-2019, viewed 28 February 2020, <http://tjj.wuhan.gov.cn/index.aspx>.

[16] 12306 CHINA RAILWAY, viewed 2 March 2020, <https://www.12306.cn/index/>.

[17] Luo, Z. (2020), The impact of new crown epidemic on economy, Capital Market and National Governance and Its Countermeasures, Finance \& Economy, 2020-2, pp. 8-15.

[18] Wang, J. (2020), the film box office in Hubei province ranked the eighth in China, Hubei Daily.

[19] Zhaopin (2019), Report on Chinese Employers' Demand and White-collar Talents Supply in Winter 2019, viewed 23 February 2020, <https://www.sohu.com/a/365616606_100020092>.

[20] Yan, Y., Chen, Y., Liu, K., Luo, X., Xu, B., Jiang, Y., Chen, J. (2020), Modeling and forecasting of COVID-19 based on a class of delayed dynamic systems, SCI: mathematics, vol. 50, no. 3, pp. 1-8.

[21] Long, W., Wang, H. \& Li, D. (2003), Simulation Analysis on the Recurrence of SARS Outbreak, Journal of Beijing University of Astronautics, vol. 16, no. 3, pp. 1-4. 